Article

\title{
Higher Sustainability and Lower Opportunistic Behaviour in Healthcare: A New Framework for Performing Hospital-Based Health Technology Assessment
}

\author{
Gabriele Palozzi, Sandro Brunelli * and Camilla Falivena \\ Department of Management and Law, University of Rome Tor Vergata, 00133 Rome, Italy; \\ palozzi@economia.uniroma2.it (G.P.); falivena@economia.uniroma2.it (C.F.) \\ * Correspondence: brunelli@economia.uniroma2.it; Tel.: +39-06-7259-5538
}

Received: 22 August 2018; Accepted: 30 September 2018; Published: 3 October 2018

check for updates

\begin{abstract}
Innovative health technology deployment represents the primary challenge within the sustainability of public health systems. On one hand, new technologies may potentially improve access to care and the quality of services. On the other hand, their rapid evolution and broad implications on existing procedures increase the risk to adopt technologies that are not value for money. As a consequence, Health Technology Assessment (HTA) is a critical process at each level of the National Health System. Focusing on the organisational level, this paper explores the current practices of Hospital-Based HTA (HB-HTA) in terms of management, control and behaviours of various actors involved. Among several tasks, decision-makers are appointed at managing the conflict of interest around health technology development, that could pave the way for corruption or other misleading behaviours. Accordingly, the purpose of the study is proposing a new strategic framework, named Health Technology Balanced Assessment (HTBA), to foster hospital-based health technology management aimed to align strategy and actions. The conceptual model is developed on three perspectives (clinical, economic and organisational) to make the actors involved in the assessment (clinicians, health professionals, hospital managers and patients) aware of the impact of new technology on the value chain. Besides supporting the decision-making process, such a tool represents support for the internal control system as a whole. By promoting structured evaluation, it increases transparency and accountability of public health organisations. Moreover, in the long run, the framework proposed will be useful to reach selected United Nations Sustainable Development Goals (UN SDGs) to enhance the quality of healthcare in the future.
\end{abstract}

Keywords: hospital-based health technology assessment; corruption; accountability; sustainability; management accounting; UN SDGs

JEL Classification: M41; H57; I18

\section{Introduction}

In many countries, health expenditure represents the primary driver of public spending. In fact the 9\% of Gross Domestic Product on average for Organisation for Economic Co-operation and Development (hereafter OECD) countries is represented by health expenditure. Among all factors of production, health technologies are commonly considered as the primary driver for burgeoning cost; indeed, $45 \%$ of health expenditure on average across the OECD countries deals with the funding of investments in health technology [1]. The acquisition of complex and/or innovative health technologies constitutes the so-called discretional expenditures, since hospital managers have 
a high autonomy in the selection of which innovations have to be adopted. New technologies can potentially improve population health, access to care and quality of life by providing a more effective service. Notwithstanding, their successful implementation is strongly influenced by the culture, structure and impacts on operative processes [2,3]. Therefore, Health Technology Assessment (HTA) to support decision-making is a critical process within both health policy and the management of health organisations towards achieving sustainable development goals. The sustainability of health systems as a whole is strongly determined by the lower levels. Hence, the sustainability of hospital care is felt to be the most important challenge by the majority of European Union Member States [4]. Due to the large number of services delivered and the amount of financial resources managed, public hospitals undergo a high risk of conducting misleading behaviours, which could undermine access to the services and their quality. In this regard, although a unique definition of corruption has not been provided yet, there is a shared agreement that "the single greatest obstacle to economic and social development" is represented by corruption $[5,6]$. Health facilities are particularly vulnerable to corruption, especially regarding procurement procedures $[7,8]$. This is the reason why the organisational dimension of HTA, named Hospital-Based HTA (HB-HTA) is fundamental in the performance planning and management of hospitals.

Over the time, many jurisdictions' reforms have operationally attempted to contain corruption through the development and/or the improvement of laws regulating corporate governance mechanisms and internal control tools in the public sector [9]. In fact, since the introduction of New Public Management (NPM) [10-12] and its evolution to the paradigm of Public Governance (PG) $[13,14]$, the separation between formulation of policy and administrative action has been considered the way to improve the efficiency and effectiveness of Public Administration, to contain opportunistic behaviours and, thus a pre-requisite for a sustainable development. Accordingly, the aim of the reforms has been to underpin performance management and increase the transparency and accountability of health organisations. However, in the last ten years, both the evidence collected in terms of missed performance targets and the financial crisis experienced, demonstrated that the results achieved were profoundly differed from the expectations.

This paper has a twofold aim: on one hand, it attempts to clarify main attributes of HTA across different levels of NHS, and to explore potential conflict of interest among actors involved within health technology deployment; on the other hand, it proposes a new theoretical framework, named the Health Technology Balanced Assessment (HTBA) to overcome main weakness and to foster a strategic approach in the management of technology. Hence, this would be a first attempt to answer to the following research question: is it possible to develop a basic general framework tool for performing HB_HTA? In particular, the challenge is promoting a more structured, informative and transparent assessment process for health technologies. The inception of HTBA is retrieved by going back to the performance management literature, identifying new solutions from it. The framework is designed on three perspectives of evaluation strictly related to hospital strategic objectives: (i) clinical; (ii) economic; (iii) organisational. The framework was developed by defining Strategic Objectives for each perspective of assessment, and, in turns, translating them into Operational Objectives measured by Key Performance Indicator (KPI). Such an approach tailors a measurement system both to the technology to be evaluated and to the specific context in which it has to be adopted. Aftermath should be an accurate definition of goals, embracing interest of all types of stakeholders and considering the overall strategy of public hospitals.

To address its purposes, the study employed a two-step approach:

1. An exploration of the literature background concerning technology adoption decision-making and the practices of HTA, with a particular focus on the hospital level;

2. The development of a conceptual framework to support hospital-based technology management, aligning strategy with operations.

Thus, the remainder of the paper is organized as follows: Section 2 addresses the theme of HB-HTA, its business function and its connection with the procurement process in the healthcare sector; 
Section 3 disentangles how corruption could take place during HTA; the fourth section proposes the new framework HTBA; Section 5 critically analyses and discusses findings by underlining the potential positive impact on misuse of managerial tools, such as the proposed framework. Finally, section six provides final remarks, forming a bridge between the new framework proposed and UN SDGs in order to clarify the pursued research pathway better and provide suggestions for further researches.

\section{Health Technology Assessment across the National Health System}

HTA is known worldwide as the process to systematically evaluate properties, effects and impacts of health technology from multidisciplinary perspectives [15]. Although it was first conceptualized in 1976 by the Office of Technology Assessment [16], its relevance has been increasing over time due to the diffusion of expensive medical equipment [17]. HTA affects the three levels-Macro, Meso and Micro- of the National Health System (NHS), supporting decision-making processes from national health policies to clinical practice [18]. Therefore, it affects the whole life cycle of health technology. At the different stages of the life cycle, HTA pursues different scopes, adopts a different approach in the evaluation and involves various stakeholders. During the phases of technology development, HTA is strongly policy-oriented in order to assess the eligibility of a new treatment and to define a reimbursement tariff. These stages involve the Macro level of the NHS, and the assessment of new technology is usually performed by national HTA agencies. These ones do not have regulative power but are appointed to produce HTA reports, that collect the best scientific evidence [3] and are not always mandatory. Recommendations mainly concern clinical and economic aspects. In particular, commonly the focus is on economic implications, referring to three categories: (a) economic information pertaining to the social perspective; (b) economic information pertaining to the hospital environment; (c) economic information pertaining both to social aspects and the hospital environment [19]. Economic information mostly deals with cost-effectiveness measurement [20] and with cost-benefit analysis [21]. The high attention given to financial aspects in the early stages of technology development is aimed at increasing transparency and reducing information asymmetry. Notwithstanding, from an opposite standpoint, such an evaluation increases the level of uncertainty since not all implications could be identified in the earlier stages [22]. Several authors underline the importance of involving "social values" in the assessment, in order to increase transparency, accountability and participation within the decision-making process [23-25]. Accordingly, an assessment of costs and outcomes from a social point of view should be added in order to estimate the burden of cost for the patient (and his/her relatives) and the consequences that health policies have on other industrial sectors. Policy makers, insurances, industries, clinicians are primarily involved in the evaluative process.

In the majority of countries, HTA deals with the negotiation of the price for pharmaceuticals and the establishment of those that are covered by public resources. More frequently, it also deals with the evaluation of medical devices and therapeutic and diagnostic procedures [26]. While in some countries, HTA refers only to health technologies aimed at treating rare diseases [27]. Significant variation among HTAs performed in different countries is due to the institutional setting and the independence of HTA bodies from Health Ministries or insurance agencies.

Once the technology has to be implemented in the clinical practice within a specific environment, the assessment process is tailored to the organisational structure and supports hospital managers in defining a technological strategy and planning investment and disinvestment. The adoption process of new technology in the hospital context follows six main steps: (i) preliminary analysis of the clinical needs and available treatment options; (ii) assessment of economic and organisational impacts as well as requisites for tenders; (iii) market analysis and consultation; (iv) choice of procurement procedure; (v) analysis of different alternatives and final decision; (vi) procurement and logistics [28]. The role of HTA at the hospital level is to provide a more locally focused technological evaluation, encompassing both general recommendations and organisational requirements [29-31]. The setting of HTA, thus, is critical since the context in which it is carried out determines the extent and comprehensiveness of the assessment $[32,33]$. HB-HTA, performing by an individual evaluator or a team, could deal 
with clinical practice and/or managerial decisions. In accordance with the matching between the focus on actions and the organisational complexity, four corporate models for carrying out HB-HTA duties are identified [34]: (i) ambassador model; (ii) internal committee; (iii) mini-HTA; (iv) HTA unit. Among these, Mini-HTA and HTA Unit are concerned with managerial decisions. Each factor of the specific setting and each person involved in the entire decision-making process affect the successful implementation of new technology in the clinical practice. Although several studies have attempted to define the best strategy to engage patients in the decision-making process to better align investment to their needs [35,36], currently only internal stakeholders are involved in HB-HTA activities. Physicians and surgeons are usually the main instigators of the introduction of new technology into hospitals [37]. Clinicians, health professionals and hospital managers perform the evaluative process, which is driven by clinical competences trying to respect budget restrictions [29,37-39]. Since drugs are already assessed by National Medicine Agencies [40], HB-HTA activities concern mainly medical devices, equipment and/or procedures [39,41-43]. Lafortune et al. argue that the evaluation objective of HB-HTA has evolved from the capital-intensive technologies to clinical outcomes and delivery models [44]. Instead, Kosherbayeva et al. state that local assessment should be focused on medical technology for which there is high demand at the regional level [45].

Figure 1 shows the three levels of HTA, highlighting the type of decision, technology evaluated, stakeholders involved and dimension assessed at each level.

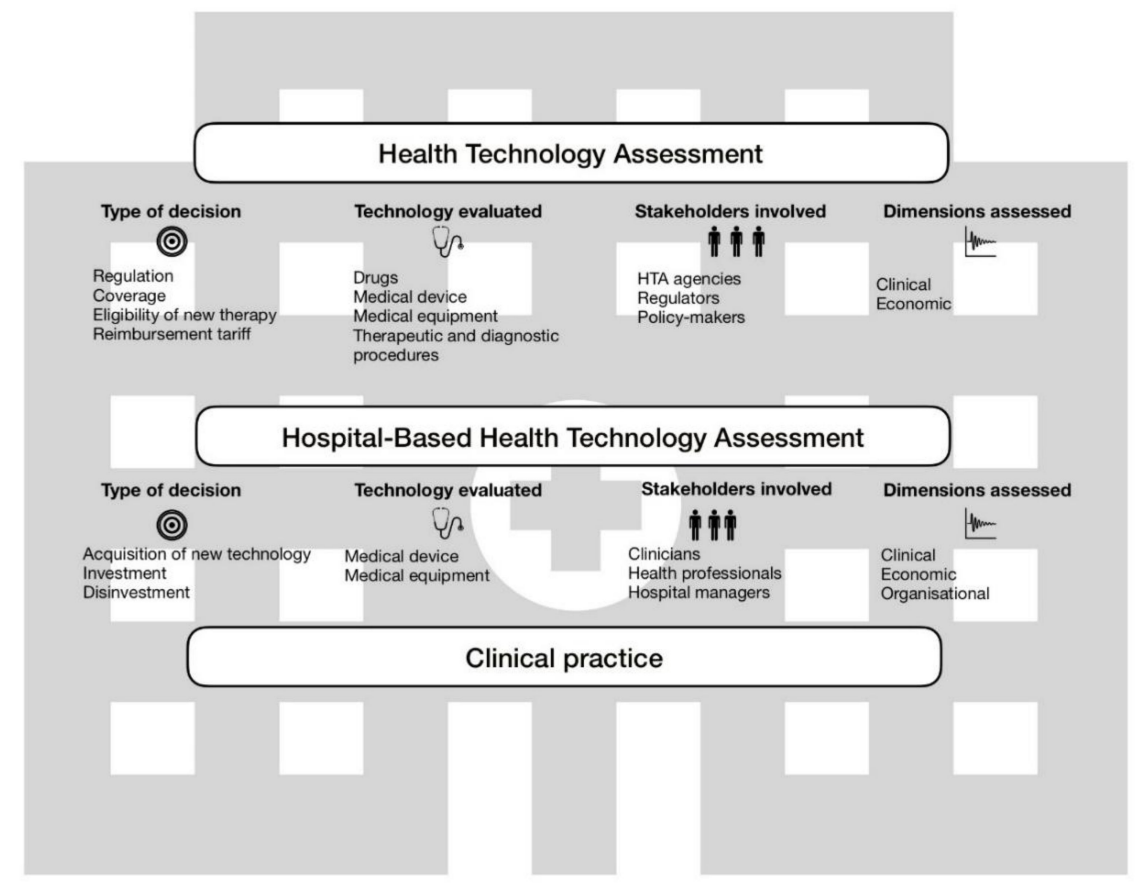

Figure 1. The Three levels of HTA.

In addition to financial issues, values of stakeholders involved, the external environment and the organisational setting could either facilitate or hinder technology implementation. Thus, the technological impact has to be assessed in relation to the health care system, the economy and society [46]. The assessment of technical and non-technical implications is relevant in particular within the primary level of care, widely considered the most effective investment in the roadmap for sustainable healthcare. Technologies aimed to support health promotion and disease prevention, in fact, foster a co-created provision of health care services between providers and users, that is transforming traditional conceptions of service planning and delivering. As a consequence, a deeper understanding of factors that influence behaviours and attitude of both organisation and people are required. First of all, it is important the understanding of the value of the science for the improvement of the quality of life [47] and alignment between benefits perceived by patients and those perceived 
by health providers [48]. Besides demographic factors and financial incentives, mutual trust and communications are critical for the achievement of health objectives $[49,50]$. In order to improve patient-provider communication and to enhance co-participation, technology is a leading asset [51]. Then, some cultural factors are relevant to determine successful stakeholder engagement. In particular, Renedo et al. identified four key elements which highlight the need for a non-hierarchical collaboration between professional and patients, supported by a constant and iterative process of data collection and reciprocal training, and a continuous adaption of behaviours toward mutual recognition and respect [52]. As a consequence, HTA activities are also appointed to manage the conflict of interest among stakeholders, balancing between the need for the best outcome for patients and the sustainable business development [53].

\section{Opportunistic Behavior in Procurement of Health Technology}

The management of the conflict of interest is critical to avoid individual bias and reducing the room for corruption. As recognised, corruption is a pervasive virus that negatively affects the public lives of many countries around the world. Many definitions of this phenomenon have been provided over time [54-56]. One of the most commonly shared definitions is the one provided by Pope [57,58] according to whom corruption is seen as "the abuse of entrusted power for private gain" [59]. The joint reading of elements defining the phenomenon (abuse, power, person(s) and private gain deriving from the abuse) determines that corruption is a consequence of one or more undesirable human actions. The damages generated by corruption lead not only to a waste of public resources but also undermine the possibility for sustainable development of countries, increase inequality and determine substantial well-being losses.

The significant burden of technological innovation within health expenditure has led the procurement process to be one of the large areas for corruption in the healthcare sector $[7,8]$. Corrupt practices and fraud, indeed, affect up to $25 \%$ of expenditure on medical and non-medical goods [60]. Improvement in the performance of public procurement might be achieved by tackling, first of all, problems related to transparency, procurement irregularities and the number of tenders to purchase equipment [4].

As stressed in the literature, the so-called institutional corruption figures fall into two types: collective and individual [61]. Focusing on the local level and transposing to the health sector the useful reasoning of Beeri and Navot [62] about local government political corruption, potential structural malfunctions could be observed at the NHS-hospital or Region-hospital level (central-local), among hospitals in competition (intra-local) or, even, among hospital managers and/or doctors in the hospital itself (local-local). In respect of procurement, opportunistic behaviours are strongly encouraged by unstoppable interactions between public and private sectors, which involve various stakeholders with different perspectives concerning the value added by health technologies [63]. Multinational corporations require adequate rewards to increase profit and to fund further researches. Public hospitals are appointed to guarantee the provision of health care, balancing the need for cost constraints with a good quality of services to create even more value for patients. Payers seek new technologies whose additional benefits justify the cost. Patients and health practitioners assess the value of health technologies in relation to benefits for the individual, irrespective of costs. Due to these different approaches among actors towards value creation, corruption represents the result of power abuses from actors, who illegally overcome rules, giving or promising different types of rewards to other actors, who join in with the opportunistic behaviours. Moreover, healthcare professionals do not always fully understand what is corruption and its impact on their work. At the same time, regulators and anti-corruption specialists often do not understand both the complexity and peculiarity of the healthcare system.

Healthcare technologies (and services derived from them) adoption and implementation are the result of a complex mosaic in which the behaviors of actors are predominant in determining final choices. The interactions among actors towards successful technology development has been explored in accordance with other perspectives, such as the patients' willingness to pay for several 
health services as a function of the distribution of information among different actors belonging to the health value chain [50]. As mentioned above, HTA involves different stakeholders throughout its steps, and not all of them are involved in all levels. Analysing the dynamics of HTA and how the decision-making process is carried out at each level of the NHS, therefore, is critical to identify trigger events that could create room for corruption from and among different actors. At the Macro level, the evaluative process concerns mainly political decisions; thus, main risks are represented by collusive agreements among politicians, civil servants and big corporations. Although it is difficult to understand how decisions taken at the Macro level could be detrimental to hospitals or healthcare authorities individually, corruption has a broad effect on healthcare [7]. Corruption from the highest levels, in fact, will trickle down to affect the health care received by patients at local healthcare facilities. If the NHS decides to adopt one technology over another, which has a lower efficacy, patients will be damaged as well as the reputation of the single healthcare "provider". Distorted policies and improper priority setting could lead to wasted resources and to a decrease in the access to treatments. Different types of criticism could be observed moving to the Meso level, where hospital managers are involved in decisions that regard purchasing and employment of health technologies into hospitals. Bargaining processes between healthcare technology providers and hospitals take place in different ways: from a generic price and volume technologies negotiations to the choice of which units, departments, even medical equips can adopt and use technologies. In this setting, corruption trigger events are represented by the possibility to alter a fair economic price, clinical efficacy, maintenance needs, usage of technologies and so on for pursuing private gains. Despite the acknowledged lack of guidelines for well-performing HT-HBA, the process must be tailored to the specific hospital context where it takes place [28]. Due to a more operations-oriented approach, clinicians have a leading part both in the selection and implementation of new technologies. In this scenario, the role of the law in regulating hospital management discretion and power, and the existence and effectiveness of the internal control system and governance rules, determine the creation of a favourable/unfavourable environment for corruption. The higher the ineffective managerial structures and control mechanisms, the higher the possibility of observing corruption [8].

Figure 2 summarises actors involved during the different stages of HTA and interactions among them.

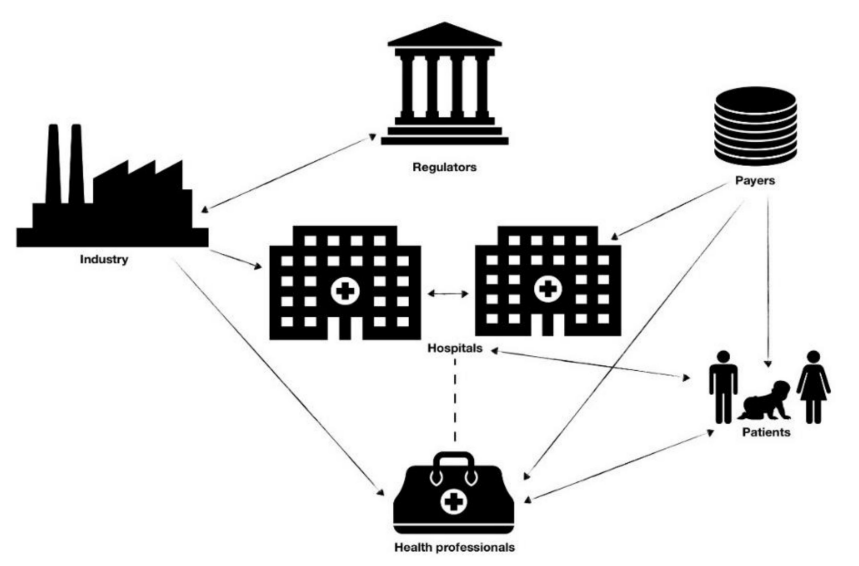

Figure 2. Actors and dynamics involved in the HTA process.

Evidence of the AdHopHTA Project $[28,64]$ emphasised how HTA phases are similar among hospitals, while comparators to be used, perspectives to be assessed, stakeholders to be engaged and tools to be adopted varied considerably. Several studies were carried out to explore if some decision-making tools could be applied to improve HB-HTA activities [29,31,42,46,65-67]; however, a scientific literature about suitable methodologies does not exist yet. Recommendations produced by HB-HTA are usually mandatory, even if decision-makers are more compliant with clinicians' requests for new technology [64]. 
Aftermaths of these approaches are investment decisions supported by inadequate or insufficient information that creates a large amount of room for pursuing opportunistic behaviours. In particular, involving only medical, safety, technical and financial issues in the assessment of new technology does not consider the relevance of organisational features towards their successful implementation. These aspects, which are already evaluated both to obtain CE marking and to introduce new technology into the NHS, have to be contextualised within a specific organisational environment.

Trying to fill some of the gaps in the current practices of HB-HTA and to foster a more structured and accountable procurement and adoption of health technologies, the next paragraph proposes a new framework: Health Technology Balanced Assessment (HTBA).

\section{4. "Health Technology Balanced Assessment" Framework}

For selecting technologies that are value for money for the organisation, the HB-HTA has to be consistent with the specific environment and oriented towards the daily management of the technology. It should consider vision, mission, critical success factors, strategies, plans and organisational structure to support better decision-making processes. Moreover, it should be able to involve all relevant perspectives and to orient the priorities of each actor towards sustainability of the system as a whole [68]. So far, the sole framework to support HTA activities is the HTA Core Model [69] proposed by the European Network for Health Technology Assessment (EUnetHTA). It covers nine domains: (i) health problem and current use of technology; (ii) description and technical characteristics; (iii) safety; (iv) clinical effectiveness; (v) costs and economic evaluation; (vi) ethical analysis; (vii) organisational aspects; (viii) patient and social aspects; (ix) legal aspects. The aim of the Model is providing a methodological approach to defining research questions within several areas. Notwithstanding, as it stands, it does not offer a tool to assess the different items.

This may be the reason why experiences of empirical application are still scarce. Moreover, due to the absence of a strategical dimension [70], it is more useful for performing HTA at early stages of new technology development.

Embracing a strategic approach in tackling HB-HTA is a serious issue in the digital era [71,72]. Technology development, in fact, can potentially improve the quality of services provided as well as the quality of life of patients. At the same time, it is transforming ways by which health care is delivered, reflected in cost, management, operations and behaviours. Therefore, sustainability of health systems is strictly related to the management of the adoption and implementation of the results of innovative technologies [73]. The sustainable development could be achieved through suitable governance models and effective practices. Accordingly, investment decisions on new technologies should be taken by balancing both the need for cost containment and the need for innovation.

As stressed previously, three main assessment perspectives are in the literature around HB-HTA: (i) clinical; (ii) economic; (iii) organisational. Each assessment perspective provides essential information in order to better identify all implications for the technology uptake. Efficacy and effectiveness are the significant concerns for clinicians and hospital managers who seek new modalities to improve the treatment of disease and who are often determined to become forerunners in their specific medical field [74]. Patients, instead, are engaged to find those treatments that could improve their health status and enhance the quality of their life. Reimbursement mechanisms and budget rules represent financial restrictions that affect decision-making and sometimes could lead to the adoption of technology that is not clinically justified [75]. Hospital capacity, specialisation and internal arrangements are critical to the successful implementation of clinical practice [64].

Performance management theories, aimed at fostering a holistic approach in the understanding and management of the value chain [76-78], could represent the basis for the development of a new management system to support HB-HTA. Performance management systems, such as the most well-known Balanced Scorecard [79], Performance Prism [80], Tableau de Bord [81] and others foster evaluation approaches supported by tools for integrating traditional accounting indicators with additional financial and non-financial measures. This way, financial assessment, through specific 
cause-effect relationships, is combined with other relevant dimensions, which may ensure the overall sustainability of investments in new technology. Similar tools contribute to the translation of strategies into actions. Notwithstanding, it is crucial to summarise the various measures and assign different priorities to support the decision to be taken. Accordingly, management systems could be aided by Multi-criteria Decision Analysis (MCDA) methods, which allows decision-makers to manage better the plethora of issues that have to be considered and to determine a solution transparently. These methods analyse and evaluate different alternatives, monitoring their impact on the various actors [82].

Summing up the importance of actors, users and their related needs, the provision of a general framework "in" and "for" hospital, named the Health Technology Balanced Assessment (HTBA), might be outlined to compare different alternatives for achieving desired results. Accordingly, the primary objective of the HTBA framework is to improve the employment of public financial resources in technological investments that have a higher value for money for the organisation.

The decision-making process complies with several phases aimed at: defining various alternatives and formulating different scenarios; assessing options by adopting several criteria, usually measured by indicators; selecting the best choice among those taken into consideration. The implementation of the HTBA framework to support decision-makers requires that some specific steps must be followed in order to increase the awareness of decision-makers and the transparency and accountability of the decision-making process.

STEP 1. The first step is the definition of relationships between perspectives of assessment and the strategic objectives of the healthcare organisation related to investments in health technology. This stage represents the basis for designing a technology strategy consistent with both the overall strategy and the structure. Regarding the three above-defined perspectives, health technology investments should first support reaching general strategic goals by:

1. improving clinical effectiveness and increasing patients' satisfaction and engagement from the clinical perspective;

2. optimising employment of financial resources, maintaining (or improving) the same level of access and quality of health services from the economic perspective;

3. improving the efficacy and effectiveness of internal processes and increasing staff satisfaction from the organisational perspective.

Figure 3 shows an example of the general HTBA framework. Starting from the HTBA mission (the grey circle), 3 couples of strategic objectives, interconnected each other are assigned to the three perspectives of appraisal. Strategic objectives could differ among hospitals; the proposed spider-graph has only the aim to shape the sorting logic of a generic HB-HTA following a balanced approach.

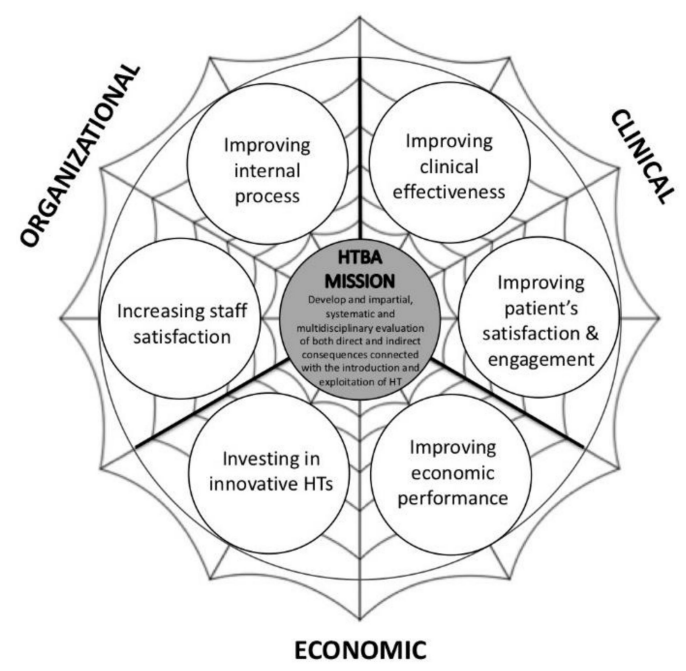

Figure 3. HTBA generic evaluation framework as a result of a strategic phase (1st HTBA step). 
STEP 2. The second step for the HTBA implementation concerns the cascading of strategic objectives into operational objectives, and the resulting definition of KPIs and related targets. This phase is critical to effectively make HTBA a support for an improved assessment of health technologies. Furthermore, defining the cause-effect relationship among strategic and operational objectives promotes the understanding of how each aspect related to the technology contributes to the attainment of desired outcomes. Referring to the three perspectives:

1. the clinical perspective deals with medical and technical issues in order to assess if a technology represents an effective treatment of a specific disease and how it works. Moreover, it is aimed at capturing patients' needs and implications, referring not only to their health status but also to their satisfaction and physiological sphere;

2. the economic perspective involves all financial issues, presented by the investment effort, cost savings or potential additional revenues;

3. the organisational perspective assesses which implications on current arrangements and procedures are by the adoption of new technology. In particular, it is performed to understand if (and which) organisational changes, in terms of roles and competencies, and training activities are required for a successful implementation.

Once operational objectives are identified, a set of KPIs has to be defined to develop a control system, which could monitor the accomplishment of performance targets within each perspective. Indicators are the expressions of criteria adopted to summarise the performance of the system under strategic alternatives to orient behaviours of the organisation. Benchmarks represented by targeted results correspond to thresholds useful for guiding the decision-making process.

Figure 4 shows the logic cascading of assessment perspective into the performance measurement system of the HTBA theoretical framework. Each perspective of technology evaluation, starting from the recognition of the specific strategic objectives, could be conveyed into operational objectives, which, in turn, are measurable by a system of KPIs. This theoretical approach takes into account both the performance achievable and its comparison with the expected target. Accordingly, this fits with general management necessities to verity if investment decisions are aligned with healthcare general mission and strategic orientation.

STEP 3. The last step of the HTBA development deals with the identification of a tool to gather and summarise the results of the assessment process. This could be represented by a dashboard that provides results of each KPI in the form of a video screen to monitor performance towards the desired targets. Such a system could clearly explain the consequences expected due to the introduction of new technology from different perspectives. The adoption of intuitive dashboards could enhance the readiness of information for all users, fostering engagement with and accountability of the HB-HTA. 


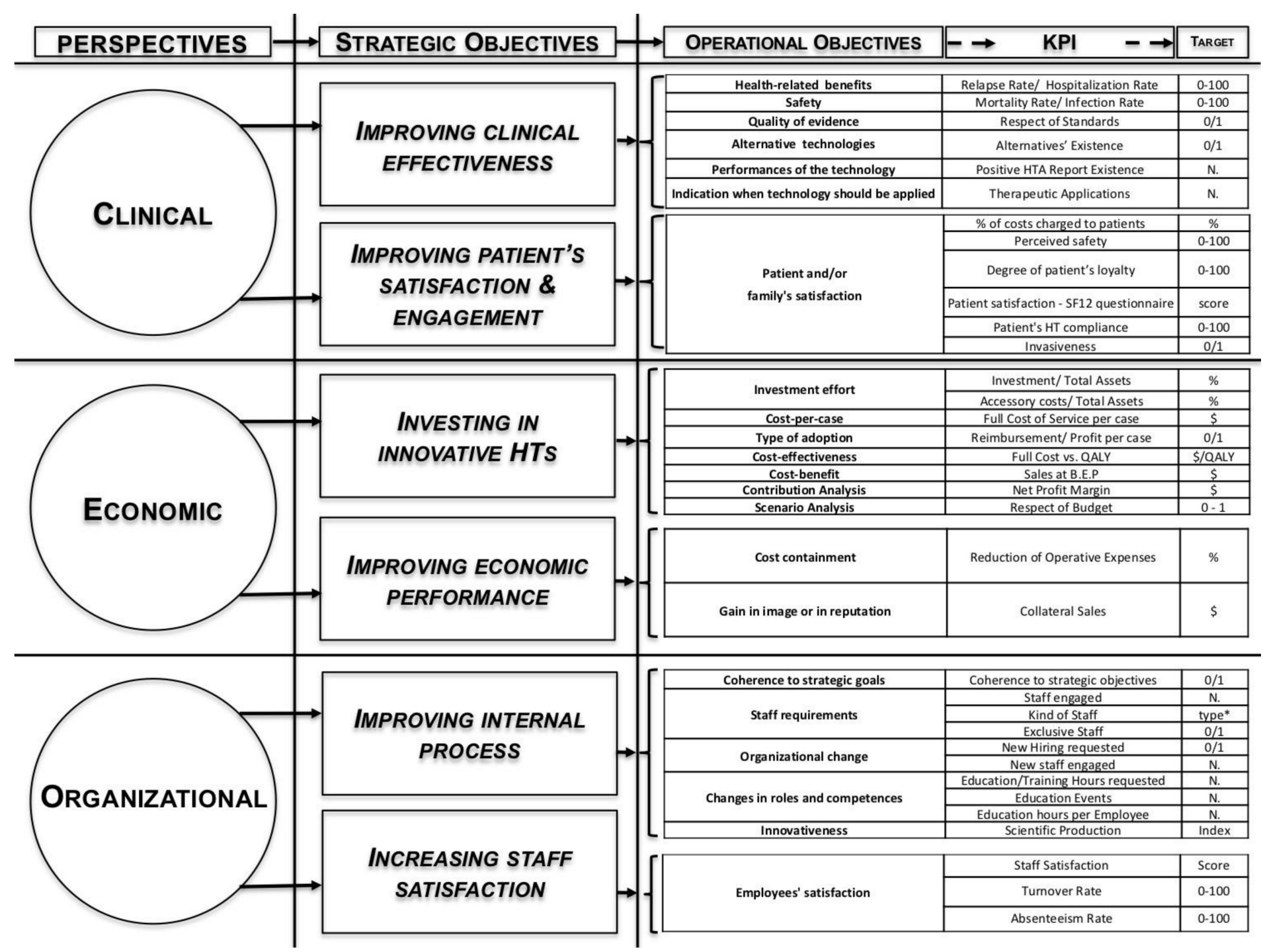

Figure 4. From strategy to operations. operational objectives and KPIs identification phase (2nd HTBA step). 
Figure 5 draws out an example of a spider graph, as a possible intuitive dashboard. The graph shows the contribution to the business performance achieved through the technology under assessment. The dashboard allows users to capture the achieved targets for each indicator linked to both operational and strategic objectives and, in turn, with the three perspectives forming the overall assessment process. Thresholds for each indicator should be established before the evaluative process. Later, by performing variance analysis, results achieved could be helpful to orientate the decision-making process. The comparison may be useful for formulating appreciations, going on with further analysis, or modifying indicators. Non-management skilled stakeholders (e.g., clinicians, patients, hospital manager with a more law focused education), in fact, are confident with customer satisfaction survey and/or questionnaire based on indicators and thresholds (for an application of the logic in the Vietnamese health sector see Vuong [83]).

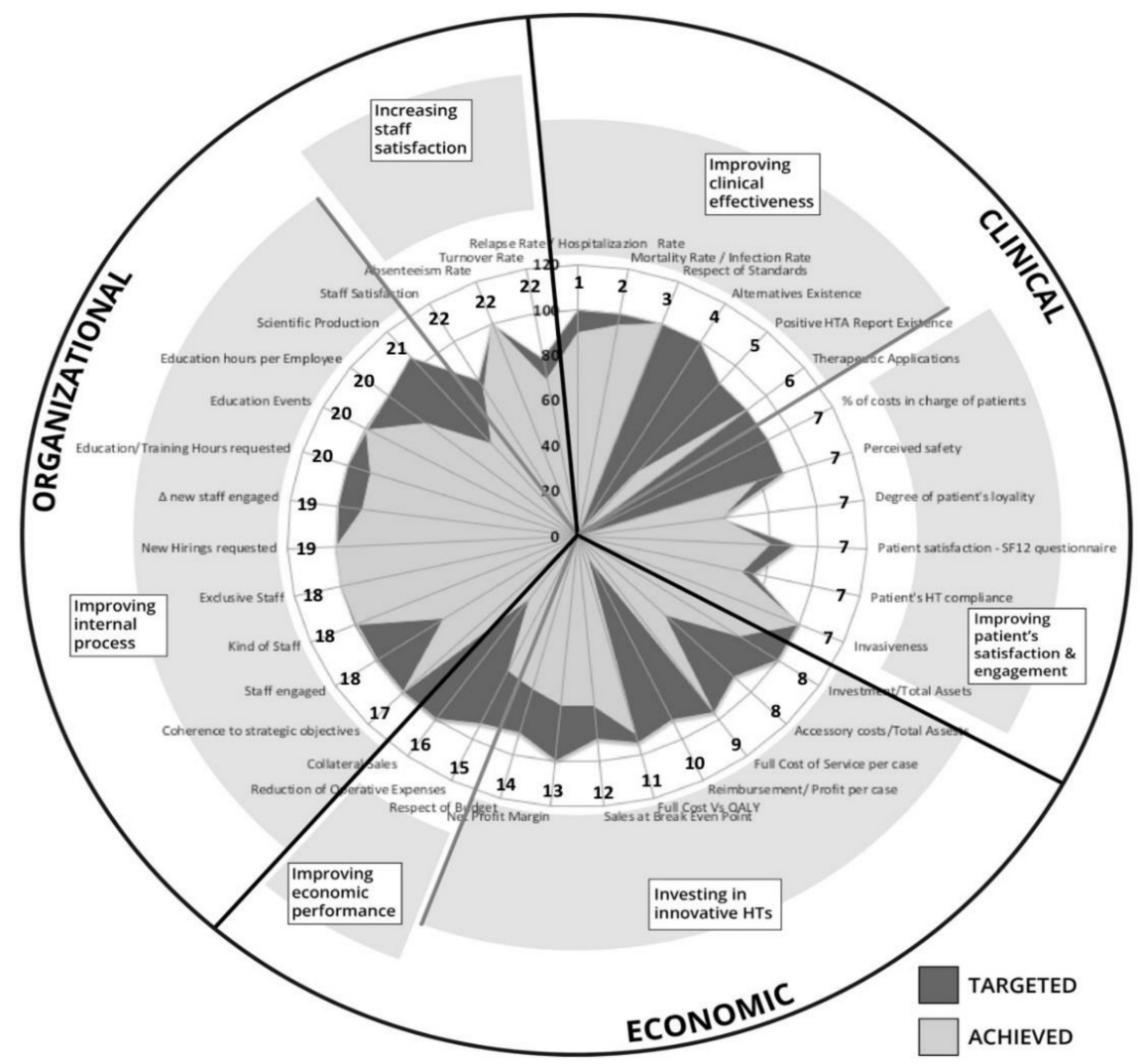

\begin{tabular}{|c|c|c|c|c|c|}
\hline \multicolumn{2}{|c|}{ CLINICAL } & \multicolumn{3}{c|}{ ECONOMIC } & \multicolumn{2}{c|}{ ORGANIZATIONAL } \\
\hline $\mathrm{n}$. & Operational Objectives & $\mathrm{n}$. & Operational Objectives & $\mathrm{n}$. & Operational Objectives \\
\hline 1 & Health-related benefits & 8 & Investment effort & 17 & Coherence to strategic goals \\
\hline 2 & Safety & 9 & Cost-per-case & 18 & Staff requirements \\
\hline 3 & Quality of evidence & 10 & Type of adoption & 19 & Organizational change \\
\hline 4 & Alternative technologies & 11 & Cost-effectiveness & 20 & $\begin{array}{c}\text { Changes in roles and } \\
\text { competences }\end{array}$ \\
\hline 5 & Performances of the technology & 12 & Cost-benefit & 21 & Innovativeness \\
\hline 6 & $\begin{array}{c}\text { Indication when technology should } \\
\text { be applied }\end{array}$ & 13 & Contribution Analysis & 22 & Employees' satisfaction \\
\hline 7 & $\begin{array}{c}\text { Patient and/or family's } \\
\text { satisfaction }\end{array}$ & 14 & Scenario Analysis & & \\
\hline & & 15 & Cost containment & & \\
\hline & & 16 & Gain in image or in reputation & & \\
\hline
\end{tabular}

Figure 5. Formalizing and monitoring performance achievements: the dashboard control. (3rd step of HTBA).

The use of the HTBA framework allows decision makers to have a complete set of information about the widespread impact of the employment of new technology within a Hospital Institution. 
In this way, HTBA becomes the operational tool for the fulfilment of the HB-HTA assignments; thus, it allows clinical managers to:

- Collect the information needed for the HT evaluation based on different qualitative and quantitative scales;

- Aggregate this information set based on specific assessment requirements;

- Analyse the results gathered by the assessment process;

- Summarise the results of the assessment in order to make them comparable with the targeted expectations.

Among all potential benefits, this pathway, more structured and formalized, could allow decision-makers to evaluate the coherence of investment choices with the general strategic orientation of the organisation to which it is applied.

\section{A Performance-Driven Hospital-Based HTA for Sustainable Development}

In order to tackle the debate around the sustainability in healthcare, several issues have to be disentangled. The first critical one concerns health system governance and, in particular, the centralisation/decentralisation of the decision-making process across the NHS. This issue is particularly significant within the procurement of health technology. Among all implications, it is important to define tasks appointed to technologies evaluated and stakeholders involved for each level of HTA. Up to now, there is still a scarce culture around HTA. In particular, it has not been understood what HB-HTA is, how it differs from HTA performed by national or regional agencies and why it may be relevant to the management of hospitals. As a consequence, hospital activities of HTA are largely neglected in favour of the HTAs conducted at the Macro level of NHS and decisions taken by single practitioners (at the Micro level). Besides, its role is restricted to the assessment phase in almost all cases. Therefore, rarely are HB-HTA activities performed by adopting a holistic approach and enlarged to other phases within health technology management and hospital management as a whole [64]. Notwithstanding, the evaluation of equipment, medical devices and procedures-usually performed at the Meso-level of NHS-requires a "managerial-rational" approach. Such an approach needs to be supported by the involvement of different competencies and, thus, by a variety of stakeholders. Healthcare professionals (both physicians and nurses) have to evaluate which alternative is easier to use and will give the best outcome for patients. Clinical engineers are appointed evaluators of technical implications and all issues regarding installation, maintenance and repair. Administrators and managers refer to economic aspects and organisational requirements, in terms of staffing and structural needs [84]. Stemming from distortions and conflicts of interests in the public procurement procedures, Directive 2014/24/EU regulated the use of different sorts of information ahead of cost [85]. This statement is forehanded in the perspective of sustainable development, strongly influenced by social, environmental and cultural dimensions besides economic aspects [86]. Therefore, different perspectives have to be reconciled to guarantee universal access to innovative and costly technologies in the future [63].

Adopting this standpoint, HB-HTA may have a broader definition, representing a process for improving strategic performance planning and the management of health facilities as a whole. Practices of HB-HTA are strongly influenced by internal and external factors that shape the design of organisational structural variables [64]. As illustrated by Drummond et al., HTA for supporting resource allocations has to comply with 15 principles [87]. The principles concern the structure of HTA of the assessment programme, methods and perspectives adopted, processes followed, and the degree of influence on the decision-making process. In order to fill gaps in the current practices of HB-HTA, the above-explained HTBA Framework could represent a tool to measure the impacts of each solution from financial and non-financial perspectives. The involvement of multidisciplinary dimensions is critical for operating in the lens of sustainability [88]. Moreover, the HTBA promotes a 
higher alignment between the selection of technologies to be adopted and the specific environment, by monitoring:

- the consistency with overall strategy;

- the cause-effect relationship among different strategic and operating objectives;

- impacts on internal processes;

- the overall sustainability of hospitals taking into consideration the external environment, social needs and patients' expectations.

Within each perspective, HTBA allows users to easily compare the results achieved both to comparators available in the clinical practice [28] and to the level of performance targeted. The understanding of implications related to innovation implementation contributes to making various stakeholders more aware of critical factors in the value chain. In addition to higher engagement, this encourages performance-driven mentality in healthcare, which has not still been developed as well as for NPM and PG's purposes [89]. Such an approach, on the one hand, increases the assumption of responsibility for management and decision-makers; on the other, it improves procurement policies and processes, the quality of technologies adopted and, as the last (but not the least) result, the well-being of citizens. A structured process of HB-HTA as well represents support in the management of the conflict of interest, which often plague the sustainability of health systems and pave the way for corruption. Due to decentralisation that usually characterises the decision-making process in the public sector, the issue of corruption has to be also explored through the agency problem lenses [90]. However, this approach for public administration is not straightforward since there is not a direct link between ownership and control as happens in private firms [91,92]. The owners of public hospitals, indeed, are citizens who cannot nominate or oversight managers directly. This mechanism implies low control and, in the end, leaves higher power and discretion in making choices in the hands of managers [93]. In addition, most of the time, when managers' misconducts arise, a higher lag in comparison with the private sector is observed in punishing or sacking them.

That is why the acknowledged need for an ex-ante better design of governance mechanisms, internal system controls and performance management tools as a whole, is felt even more in the public sector. Further, in organisations that are social value-oriented, such as those in the health sector, performance measurement activities are more difficult as the monetary unit loses a considerable part of its efficacy in evaluating results. As contended in the literature [94-97], the best way to minimise this loss in capturing the value created is represented by striving efforts towards better accountability. However, if higher accountability in the past was required for better figuring out performance achieved, today it is essential for preventing opportunistic behaviours, and avoiding information losses [98].

It is clear that for one that gains from misconducts, there is another one (or more) that incurs a loss. Referring this reasoning to public hospitals can easily allow us to conclude that the losers usually are represented by patients, and related damages could be catastrophic. Internalizing the cost of (or the loss generated by) misconducts, even corruption [99] is, therefore, the result of two main components: governance mechanisms and internal control systems adopted.

Implications of corruption in the procurement of health technology are mainly represented by the acquisition of low-quality and ineffective products, that are not aligned with health needs [7]. Misleading behaviours sometimes lead to the introduction of innovative treatments whose high cost could increase inequalities. Inability and/or willingness to pay for medical services, indeed, is commonly considered as the primary barrier to access to care from patients' standpoint [4].

Accordingly, the proposed framework would attempt to involve the different perspectives of various stakeholders and all relevant issues to identify the implications of new technology on organisational context. Among all potential benefits, HTBA should be able to increase awareness in the decision-making process, boosting public hospitals' accountability and transparency $[100,101]$. 


\section{Final Remarks}

In the analysis of the value created by healthcare organisations, the social perspective seems to be the most important. Accordingly, we may interpret the concept of value-added in terms of social value-added. Features such as economic productivity, diversification, upgrading and innovation of technologies are the essence within the process of value creation. These aspects are also the basis for planning hospital capacities by adopting a comprehensive approach.

After the research pathway aimed at depicting the existing weaknesses of HB-HTA practices and then at proposing a new model for overcoming these weaknesses, we undertaken a holistic reading of UN SDGs. The aim was to prompt reflections around the usefulness of the model in achieving several of them.

First of all, the focus on the local level is strictly related to the belief that increasing the sustainability of hospital care is critical for improving the sustainability of the health system as a whole. Issues such as universal health coverage, access to quality essential care services, safety and effectiveness could be achieved only if hospitals move towards a more sustainable technological development. Assessing relevant issues of the three perspectives (clinical, organisational and economical) of the proposed model is critical for the achievement of the afore-mentioned objectives (UN SDG 3). As seen, previous studies dealt, on the one hand, with the need for tailored HB-HTA procedures in the light of the peculiarities of organisations; on the other, they provided evidence of successful experiences of HB-HTA. However, there are no studies, apart from this attempt, privileging the managerial and control perspectives for improving the procurement processes of public hospitals (UN SDG 12) taking into account different interests involved in the process.

Due to diversities among jurisdictions and realities, many are the trigger events where maladministration or even corruption could affect procurement procedures. To promote, sustainable public procurement practices, interests of all stakeholders involved and, in the end, the interest owned by patients have to be balanced. Better accountability and transparency together with less corruption within public hospitals' technologies acquisition processes could be pursued only through a general framework when performing HT evaluation (UN SDG 16). A structured Meso level of HTA could countervail between political pressures coming from the Macro level and personal abuses of entrusted power coming from the Micro level.

An advanced, sustainable management accounting tool for promoting better decisions could be significant towards the achievement of higher innovation, productivity and social value (UN SDG 8). Otherwise, by referring only to the right intuitions from physicians and/or managers we might win some battles but never the war.

In conclusion, in accordance with Ball and Bebbington [88], this paper has tried to answer how public health organisations could effectively disentangle their responsibilities for sustainable development performance. Moreover, passing through accounting techniques useful to guide public sector organisations' actions, and to what accounts may describe their performance, we tried to build the bases for better accountability.

Further researches might address the application of the proposed model in different public healthcare organisations and across jurisdictions to test its rationale and effectiveness and to improve it continuously. For academics, we encourage contributions aimed at enriching the inner logic of the model. In this respect, contributions from hospital managers and physicians would also be desirable.

Author Contributions: Although the work is a result of a joint efforts by all authors, the paper conceptualization is due to G.P.; funding acquisition and supervision to S.B.; methodology to C.F. All authors have been involved in writing the original draft, anyway paragraphs can be attributed as follows: $\S 1$ S.B. and C.F., § 2 C.F., § 3 S.B., $\S 4$ C.F. and G.P., § 5 S.B. and C.F., § 6 C.F. and G.P.

Funding: This research was funded by University of Rome Tor Vergata. This paper is one of the results of the project "Fostering the debate between continuity, ethics and overall sustainability of the firm: Building a new theory for the survivor and growth of the firms", grant number "SustGc17", which sees Dr. Sandro Brunelli as principal investigator. All information about the public competition and resource granted are available at: https://web.uniroma2.it/module/name/Content/action/showpage/content_id/22793. 
Conflicts of Interest: The Authors declare no conflict of interest.

\section{References}

1. Organisation for Economic Co-operation and Development (OECD). Health at a Glance 2015: OECD Indicators; OECD Publishing: Paris, France, 2015. [CrossRef]

2. Velasco Garrido, M.; Kristensen, F.B.; Nielsen, C.P.; Busse, R. Health Technology Assessment and Health Policy-Making in Europe: Current Status, Challenges and Potential; World Health Organization on Behalf of the European Observatory on Health Systems and Policies: London, UK, 2008; ISBN 9789289042932.

3. Nielsen, C.P.; Funch, T.M.; Kristensen, F.B. Health Technology Assessment: Research Trends and Future Priorities in Europe. J. Health Ser. Res. Policy 2011, 16, 6-15. [CrossRef] [PubMed]

4. Commission Services (Directorate-General for Economic and Financial Affairs); Economic Policy Committee (Ageing Working Group). Joint Report on Health Care and Long-Term Care Systems \& Fiscal Sustainability; European Commission: Brussels, Belgium, 2016; Volume 1. Available online: https://publications.europa. eu/en/publication-detail/-/publication/d6042a45-b535-11e6-9e3c-01aa75ed71a1/language-en (accessed on 25 July 2018).

5. Braithwaite, J. Flipping markets to virtue with qui tam and restorative justice. Account. Org. Soc. 2013, 38, 458-468. [CrossRef]

6. Neu, D.; Everett, J.; Rahaman, A.S.; Martinez, D. Accounting and networks of corruption. Account. Org. Soc. 2013, 38, 505-524. [CrossRef]

7. Petkov, M.; Cohen, D. Diagnosing Corruption in Healthcare; Transparency International: London, UK, October 2016; ISBN 9781910778609.

8. European Union. Updated Study on Corruption in the Healthcare Sector; Final Report; Publications Office of the European Union: Luxembourg, 2017. [CrossRef]

9. Cooper, D.J.; Dacin, T.; Palmer, D. Fraud in accounting, organizations and society. Account. Org. Soc. 2013, 38, 440-457. [CrossRef]

10. Hood, C. A Public Management for All Seasons. Public Adm. 1991, 69, 3-19. [CrossRef]

11. Dunleavy, P.; Hood, C. From Old Public Administration to New Public Management. Public Money Manag. 1994, 14, 9-16. [CrossRef]

12. Barberis, P. The New Public Management and a New Accountability. Public Adm. 1998, 76, 451-470. [CrossRef]

13. Osborne, S.P. The New Public Governance? Public Manag. Rev. 2006, 8, 377-387. [CrossRef]

14. Bovaird, A.G.; Bovaird, T.; Löffler, E. Public Management and Governance, 2nd ed.; Routledge: London, UK, 2009; ISBN 0415430429.

15. World Health Organization. Institutionalisation of Health Technology Assessment: Report of a WHO Meeting, Bonn, Germany, June 30-July 1 2001; WHO Regional Office for Europe: Copenhagen, Denmark, 2001.

16. Office of Technology Assessment. Development of Medical Technology: Opportunities for Assessment; Government Printing Office: Washington, DC, USA, 1976.

17. Jonsson, E.; Banta, D. Management of health technologies: An international view. BMJ 1999, $319,1293$. [CrossRef] [PubMed]

18. Battista, R.N. Towards a paradigm for technology assessment. In The Scientific Basis of Health Services; Peckham, M., Smith, R., Eds.; BMJ Publishing Group: London, UK, 1996.

19. Kidholm, K.; Ølholm, A.M.; Birk-Olsen, M.; Cicchetti, A.; Fure, B.; Halmesmäki, E.; Kahveci, R.; Kiivet, R.-A.; Wasserfallen, J.B.; Wild, C.; et al. Hospital Managers' Need for Information in Decision-Making: An Interview Study in Nine European Countries. Health Policy 2015, 119, 1424-1432. [CrossRef] [PubMed]

20. Moreno, E.; Girón, F.J.; Vázquez-Polo, F.J.; Negrín, M.A. A Bayesian Net Benefit Approach to Cost-Effectiveness Analysis in Health Technology Assessment. Int. J. Econ. Bus. 2009, 16, 323-345. [CrossRef]

21. Craven, M.P.; Morgan, S.P.; Crowe, J.A.; Lu, B. Deploying a spreadsheet tool for early economic value assessment of medical device innovations with healthcare decision makers. J. Manag. Mark. Healthc. 2009, 2, 278-292. [CrossRef]

22. Hartz, S.; John, J. Public health policy decisions on medical innovations: What role can early economic evaluation play? Health Policy 2009, 89, 184-192. [CrossRef] [PubMed] 
23. Douw, K.; Vondeling, H.; Oortwijn, W. Priority setting for horizon scanning of new health technologies in Denmark: Views of health care stakeholders and health economists. Health Policy 2006, 76, 334-345. [CrossRef] [PubMed]

24. Clark, S.; Weale, A. Social values in health priority setting: A conceptual framework. J. Health Organ. Manag. 2012, 26, 293-316. [CrossRef] [PubMed]

25. Whitty, J.A.; Littlejohns, P. Social values and health priority setting in Australia: An analysis applied to the context of health technology assessment. Health Policy 2015, 119, 127-136. [CrossRef] [PubMed]

26. Commission Services (Directorate-General for Economic and Financial Affairs); Economic Policy Committee (Ageing Working Group). Joint Report on Health Care and Long-Term Care Systems E Fiscal Sustainability; Country Documents; European Commission: Brussels, Belgium, 2016; Volume 2. Available online: https:/ / publications.europa.eu/en/publication-detail/-/publication/8f7a1f6b-b538-11e69e3c-01aa75ed71a1/language-en (accessed on 25 July 2018).

27. Levy, A.R.; Mitton, C.; Johnston, K.M.; Harrigan, B.; Briggs, A.H. International Comparison of Comparative Effectiveness Research in Five Jurisdictions. PharmacoEconomics 2010, 28, 813-830. [CrossRef] [PubMed]

28. Sampietro-Colom, L.; Lach, K.; Cicchetti, A.; Kidholm, K.; Pasternack, I.; Fure, B.; Rosenmöller, M.; Wild, C.; Kahveci, R.; Wasserfallen, J.B.; et al. The AdHopHTA handbook: A Handbook of Hospital-Based Health Technology Assessment (HB-HTA); Public Deliverable; The AdHopHTA Project (FP7/2007-13 Grant Agreement nr. 305018). 2015. Available online: http:/ / www.adhophta.eu/handbook (accessed on 20 July 2018).

29. Knies, S.; Lombardi, G.; Commers, M.; Douben, H.P.; Evers, S.; Michelsen, K.; Oortwijn, W.; Opara, C.; Brand, H. Supporting decision making in cross-border regions: A health technology assessment tool for hospitals. Int. J. Technol. Assess. Health Care 2013, 29, 71-78. [CrossRef] [PubMed]

30. Martelli, N.; Lelong, A.S.; Prognon, P.; Pineau, J. Hospital-Based Health Technology Assessment for Innovative Medical Devices in University Hospitals and the Role of Hospital Pharmacists: Learning from International Experience. Int. J. Technol. Assess. Health Care 2013, 29, 185-191. [CrossRef] [PubMed]

31. Martelli, N.; Hansen, P.; van den Brink, H.; Boudard, A.; Cordonnier, A.L.; Devaux, C.; Pineau, J.; Prognon, P.; Borget, I. Combining Multi-Criteria Decision Analysis and Mini-Health Technology Assessment: A Funding Decision-Support Tool for Medical Devices in a University Hospital Setting. J. Biomed. Inform. 2016, 59, 201-208. [CrossRef] [PubMed]

32. Banta, D. The development of health technology assessment. Health Policy 2003, 63, 121-132. [CrossRef]

33. Velasco Garrido, M.; Busse, R. Health Technology Assessment-An Introduction on Objectives, Role of Evidence, and Structure in Europe; European Observatory on Health Systems and Policies: Brussels, Belgium, 2005.

34. Cicchetti, A.; Marchetti, M.; Dibidino, R.; and Corio, M. Hospital Based Health Technology Assessment World-Wide Survey; Hospital Based Health Technology Assessment Sub-Interest Group: Roma, Italy, 2008; 41p.

35. Gagnon, M.P.; Lepage-Savary, D.; Gagnon, J.; St-Pierre, M.; Simard, C.; Rhainds, M.; Lemieux, R.; Gauvin, F.P.; Desmartis, M.; Légaré, F. Introducing patient perspective in health technology assessment at the local level. BMC Health Serv. Res. 2009, 9, 54. [CrossRef] [PubMed]

36. Gagnon, M.P.; Gagnon, J.; St-Pierre, M.; Gauvin, F.; Piron, F.; Rhainds, M.; Coulombe, M.; Lepage-Savary, D.; Desmartis, M.; Dipankui, M.T.; et al. Involving patients in HTA activities at local level: A study protocol based on the collaboration between researchers and knowledge users. BMC Health Serv. Res. 2012, 12, 14. [CrossRef] [PubMed]

37. Billaux, M.; Borget, I.; Prognon, P.; Pineau, J.; Martelli, N. Innovative medical devices and hospital decision making: A study comparing the views of hospital pharmacists and physicians. Aust. Health Rev. 2016, 40, 257-261. [CrossRef] [PubMed]

38. Demirdjian, G. A 10-Year Hospital-Based Health Technology Assessment Program in A Public Hospital in Argentina. Int. J. Technol. Assess. Health Care 2015, 31, 103-110. [CrossRef] [PubMed]

39. Martelli, N.; Billaux, M.; Borget, I.; Pineau, J.; Prognon, P.; van den Brink, H. Introduction of Innovative Medical Devices at French University Hospitals: An Overview of Hospital-Based Health Technology Assessment Initiatives. Int. J. Technol. Assess. Health Care 2015, 31, 12-18. [CrossRef] [PubMed]

40. Halmesmäki, E.; Pasternack, I.; Roine, R. Hospital-based health technology assessment (HTA) in Finland: A case study on collaboration between hospitals and the national HTA unit. BMC Health Res. Policy Syst. 2016, 14, 25. [CrossRef] [PubMed]

41. Gagnon, M.P. Hospital-Based Health Technology Assessment: Developments to Date. PharmacoEconomics 2014, 32, 819-824. [CrossRef] [PubMed] 
42. Sampietro-Colom, L.; Morilla-Bachs, I.; Gutierrez-Moreno, S.; Gallo, P. Development and Test of a Decision Support Tool for Hospital Health Technology Assessment. Int. J. Technol. Assess. Health Care 2012, 28, 460-465. [CrossRef] [PubMed]

43. Tedesco, G.; Faggiano, F.C.; Leo, E.; Derrico, P.; Ritrovato, M. A Comparative Cost Analysis of Robotic-Assisted Surgery versus Laparoscopic Surgery and Open Surgery: The Necessity of Investing Knowledgeably. Surg. Endosc. 2016, 30, 5044-5051. [CrossRef] [PubMed]

44. Lafortune, L.; Farand, L.; Mondou, I.; Sicotte, C.; Battista, R. Assessing the Performance of Health Technology Assessment Organizations: A Framework. Int. J. Technol. Assess. Health Care 2008, 24, 76-86. [CrossRef] [PubMed]

45. Kosherbayeva, L.; Hailey, D.; Kurakbaev, K.; Tsoy, A.; Zhuzzhanov, O.; Donbay, A.; Kumar, A.; Nadyrov, K. Implementation of Health Technology Assessment Work in a Hospital in Kazakhstan. Int. J. Technol. Assess. Health Care 2016, 32, 78-80. [CrossRef] [PubMed]

46. Miniati, R.; Dori, F.; Cecconi, G.; Gusinu, R.; Niccolini, F.; Biffi Gentili, G. HTA decision support system for sustainable business continuity management in hospitals. The case of surgical activity at the University Hospital in Florence. Technol. Health Care 2013, 21, 49-61. [CrossRef] [PubMed]

47. Vuong, Q.H. The (ir)rational consideration of the cost of science in transition economies. Nat. Hum. Behav. 2018, 2, 5. [CrossRef]

48. Hardyman, W.; Daunt, K.L.; Kitchener, M. Value Co-Creation through Patient Engagement in Health Care: A micro-level approach and research agenda. Public Manag. Rev. 2015, 17, 90-107. [CrossRef]

49. Van Eijk, C.J.A.; Steen, T.P.S. Why People Co-Produce: Analysing citizens' perceptions on co-planning engagement in health care services. Public Manag. Rev. 2014, 16, 358-382. [CrossRef]

50. Vuong, Q.H.; Ho, M.T.; Nguyen, H.K.; Vuong, T.T. Healthcare consumers' sensitivity to costs: A reflection on behavioural economics from an emerging market. Palgrave Commun. 2018, 4, 70. [CrossRef]

51. Palumbo, R. Contextualizing co-production of health care: A systematic literature review. Int. J. Public Sect. Manag. 2016, 29, 72-90. [CrossRef]

52. Renedo, A.; Marston, C.A.; Spyridonidis, D.; Barlow, J. Patient and Public Involvement in Healthcare Quality Improvement: How organizations can help patients and professionals to collaborate. Public Manag. Rev. 2015, 17, 17-34. [CrossRef]

53. Gurtner, S. Making the Right Decisions about New Technologies: A Perspective on Criteria and Preferences in Hospitals. Health Care Manag. Rev. 2014, 39, 245-254. [CrossRef] [PubMed]

54. Bardhan, P. Corruption and Development: A Review of Issues. J. Econ. Lit. 1997, 35, 1320-1346.

55. Mauro, P. Corruption and the Composition of Public Expenditure. J. Public Econ. 1998, 69, 263-279. [CrossRef]

56. Liu, E. A historical review of the control of corruption on economic crime in China. J. Financ. Crime 2016, 23, 4-21. [CrossRef]

57. Pope, J. Confronting Corruption: The Elements of a National Integrity System; Transparency International: London, UK, 2000; ISBN 3980565785.

58. Pope, J. National Integrity Systems: The key to building sustainable, just and honest government. In Promoting Integrity. Evaluating and Improving Public Institutions; Head, B.W., Brown, A.J., Connors, C., Eds.; Ashgate Publishing: Aldershot, UK, 2008; pp. 28-29.

59. Organisation for Economic Co-operation and Development (OECD). Corruption: Glossary of International Criminal Standards; OECD Publishing: Paris, France, 2008; Available online: http://www.oecd.org/ corruption/corruptionglossaryofinternationalcriminalstandards.htm (accessed on 24 July 2018).

60. Sorenson, C.; Kanavos, P. Medical technology procurement in Europe: A cross-country comparison of current practice and policy. Health Policy 2011, 100, 43-50. [CrossRef] [PubMed]

61. Palmer, D. Extending the process Model of Collective Corruption. Res. Organ. Behav. 2008, 28, 107-135. [CrossRef]

62. Beeri, I.; Navot, D. Local Political Corruption: Potential structural malfunctions at the central-local, local-local and intra-local levels. Public Manag. Rev. 2012, 15, 712-739. [CrossRef]

63. Drummond, M.; Tarricone, R.; Torbica, A. Assessing the Added Value of Health Technologies: Reconciling Different Perspectives. Value Health 2013, 16, 7-13. [CrossRef] [PubMed] 
64. Cicchetti, A.; Iacopino, V.; Coretti, S.; Fiore, A.; Marchetti, M.; Sampietro-Colom, L.; Kidholm, K.; Wasserfallen, J.-B.; Kahveci, R.; Halmesmäki, E.; et al. Toward a Contingency Model for Hospital-Based Health Technology Assessment: Evidence from AdHopHTA Project. Int. J. Technol. Assess. Health Care 2018, 34, 205-211. [CrossRef] [PubMed]

65. Miniati, R.; Frosini, F.; Cecconi, G.; Dori, F.; Biffi Gentili, G. Development of Sustainable Models for Technology Evaluation in Hospital. Technol. Health Care 2014, 22, 729-739. [CrossRef] [PubMed]

66. Poulin, P.; Austen, L.; Scott, C.M.; Waddell, C.D.; Dixon, E.; Poulin, M.; Lafrenière, R. Multi-Criteria Development and Incorporation into Decision Tools for Health Technology Adoption. J. Health Organ. Manag. 2013, 27, 246-265. [CrossRef] [PubMed]

67. Ritrovato, M.; Faggiano, F.C.; Tedesco, G.; Derrico, P. Decision-Oriented Health Technology Assessment: One Step Forward in Supporting the Decision-Making Process in Hospitals. Value Health 2015, 18, 505-511. [CrossRef] [PubMed]

68. Barile, S. Introduzione. In Condizioni di Efficacia Relazionale e di Performance Dell'azienda Sanitaria; Saviano, M., Ed.; Giappichelli: Torino, Italy, 2012; pp. 11-13. ISBN 9788834838938.

69. EUnetHTA. The HTA Core Model ${ }^{\circledR}$. Guiding Principles on Use. 2015. Available online: https:/ / www.eunethta.eu/wp-content/uploads/2018/01/The-HTA-Core-Model_Guiding-principleson-use_20151218.pdf (accessed on 25 September 2018).

70. Ølholm, A.M.; Kidholm, K.; Birk-Olsen, M.; Christensen, J.B. Hospital Managers' Need for Information on Health Technology Investments. Int. J. Technol. Assess. Health Care 2015, 31, 414-425. [CrossRef] [PubMed]

71. Gastaldi, L.; Corso, M. Smart healthcare digitalization: Using ICT to effectively balance exploration and exploitation within hospitals. Int. J. Eng. Bus. Manag. 2012, 4, 4-9. [CrossRef]

72. Berman, S.; Marshall, A. The next digital transformation: From an individual-centered to an everyone-to-everyone economy. Strateg. Leadersh. 2014, 42, 9-17. [CrossRef]

73. Barile, S.; Polese, F.; Antonucci, E.; Carrubbo, L. Al confine dell'innovazione tecnologica in sanità: La medicina traslazionale. In Le Responsabilità in Ambito Sanitario; Aleo, S., De Matteis, R., Vecchio, G., Eds.; CEDAM: Milano, Italy, 2014; Volume 1, pp. 1233-1267. ISBN 9788813347079.

74. Cappellaro, G.; Fattore, G.; Torbica, A. Funding health technologies in decentralized systems: A comparison between Italy and Spain. Health Policy 2009, 92, 313-321. [CrossRef] [PubMed]

75. Galani, C.; Rutten, F.F. Self-reported healthcare decision-makers' attitudes towards economic evaluations of medical technologies. Curr. Med. Res. Opin. 2008, 24, 3049-3058. [CrossRef] [PubMed]

76. Otley, D. Performance management: A framework for management control systems research. Manag. Account. Res. 1999, 10, 363-382. [CrossRef]

77. Lebas, M.; Euske, K. A conceptual and operational delineation of performance. In Business Performance Measurement: Theory and Practice; Neely, A., Ed.; Cambridge University Press: Cambridge, UK, 2002; pp. 65-79. ISBN 0511041578.

78. Ferreira, A.; Otley, D. The Design and Use of Performance Management Systems: An Extended Framework for Analysis. Manag. Account. Res. 2009, 20, 263-282. [CrossRef]

79. Kaplan, R.S.; Norton, D.P. The Balanced Scorecard: Translating Strategy into Action; Harvard Business School Press: Boston, MA, USA, 1996; ISBN 9780875846514.

80. Neely, A.; Adams, C.; Crowe, P. The performance prism in practice. Meas. Bus. Excell. 2001, 5, 6-13. [CrossRef]

81. Fernandez, A. Les Nouveaux Tableaux de Bord des Managers: Le Projet Business Intelligence Clés en Main, 6th ed.; Eyrolles: Paris, France, 2013; ISBN -13.

82. Figueira, J.; Greco, S.; Ehrgott, M. Multiple Criteria Decision Analysis: State of the Art Surveys; Springer: New York, NY, USA, 2005; pp. 4-7. ISBN 9780387230818.

83. Vuong, Q.H. Sociodemographic Factors Influencing Vietnamese Patient Satisfaction with Healthcare Services and Some Meaningful Empirical Thresholds. Iran. J. Public Health 2018, 47, 119-126. [PubMed]

84. Sloane, E.B.; Liberatore, M.J.; Nydick, R.L.; Luo, W.; Chung, Q.B. Using the Analytic Hierarchy Process as a Clinical Engineering Tool to Facilitate an Iterative, Multidisciplinary, Microeconomic Health Technology Assessment. Comput. Oper. Res. 2003, 30, 1447-1465. [CrossRef]

85. European Union. Directive 2014/24/EU of the European Parliament and of the Council of 26 February 2014 on public procurement and repealing Directive 2004/18/EC. Off. J. Eur. Union 2014, 65-242. Available online: http:/ / data.europa.eu/eli/dir/2014/24/oj (accessed on 20 July 2018). 
86. Bebbington, J.; Brown, J.; Frame, B. Accounting technologies and sustainability assessment models. Ecol. Econ. 2007, 61, 224-236. [CrossRef]

87. Drummond, M.F.; Schwartz, J.; Luce, B.R.; Neumann, P.J.; Siebert, U.; Sullivan, S.D. Key principles for the improved conduct of health technology assessments for resource allocation decisions. Int. J. Technol. Assess. Health Care 2008, 24, 244-258. [CrossRef] [PubMed]

88. Ball, A.; Bebbington, J. Editorial: Accounting and Reporting for Sustainable Development in Public Service Organizations. Public Money Manag. 2008, 28, 323-326. [CrossRef]

89. Silva, P.; Ferreira, A. Performance management in primary healthcare service: Evidence from a field study. Qual. Res. Account. Manag. 2010, 7, 424-449. [CrossRef]

90. Fama, E.F.; Jensen, M.C. Separation of ownership and control. J. Law Econ. 1983, 26, 301-325. [CrossRef]

91. Mulgan, R. 'Accountability': An Ever Expanding Concept. Public Adm. 2000, 78, 555-573. [CrossRef]

92. Fowler, C.J.; Cordery, C. From Community to Public Ownership: A Tale of Changing Accountabilities. Account. Audit. Account. J. 2015, 28, 128-153. [CrossRef]

93. Klitgaard, R. Controlling Corruption, 1st ed.; University of California Press: Berkeley, CA, USA, 1988; ISBN 9780520074088.

94. Carnegie, G.D.; West, B.P. Making Accounting Accountable in the Public Sector. Crit. Perspect. Account. 2005, 16, 905-928. [CrossRef]

95. Osborne, S.P.; Ball, A. Social Accounting and Public Management. Accountability for the Public Good, 1st ed.; Routledge: London, UK, 2010; ISBN 9780415806497.

96. Bracci, E.; Humphrey, C.; Moll, J.; Steccolini, I. Public Sector Accounting, Accountability and Austerity: More Than Balancing the Books? Account. Audit. Account. J. 2015, 28, 878-908. [CrossRef]

97. Newberry, S. Public Sector Accounting: Shifting Concepts of Accountability. Public Money Manag. 2015, 35, 371-376. [CrossRef]

98. Christensen, M.; Skærbæk, P. Framing and Overflowing of Public Sector Accountability Innovations. Account. Audit. Account. J. 2007, 20, 101-132. [CrossRef]

99. D’Onza, G.; Brotini, F.; Zarone, V. Disclosure on Measures to Prevent Corruption Risks: A Study of Italian Local Governments. Int. J. Public Adm. 2017, 40, 612-624. [CrossRef]

100. Kassel, D.S. Performance, Accountability, and the Debate over Rules. Public Adm. Rev. 2008, 68, $241-252$. [CrossRef]

101. Barrett, P. New Development: Financial Reform and Good Governance. Public Money Manag. 2014, 34, 59-66. [CrossRef] 